"Volume 14, No. 2, Desember 2020"

\title{
PEMIKIRAN FIQH DAN TASAWWUF SYEKH MUHAMMAD NAWAWI BANTEN DAN PENGARUHNYA TERHADAP MODERASI BERAGAMA DAN PERDAMAIAN
}

\author{
Oleh \\ Ahmad Muzakki \\ Institut Ilmu Keislaman Zainul Hasan Genggong Probolinggo \\ muzakkipasca@gmail.com
}

\begin{abstract}
:
Syekh Muhammad Nawawi Banten is a figure of the Indonesian Ulama who has a major contribution in Islamic law and the formation of national character. His works cover various disciplines. Syekh Nawawi is one of the scholars who are able to combine science of jurisprudence and tasawwuf. In his Sufi fiqh thinking there are a number of moderation values that affect peace. This study uses literature and conceptual studies. The values of moderation in fiqh thinking include always trying to minimize differences of opinion, tolerant in the midst of differences of opinion madzhab, be careful (ihtiyath) in setting the law, and not fanatic madzhab. While among moderate thoughts in Sufism is the teaching about the combination of Shari'a, Tariqot and the nature, between tawakkal and endeavor in seeking income. The values of moderation in the thought of fiqh and tasawwuf Shaykh Nawawi Banten are very influential in shaping the nation's character and creating peace. This can be seen from the moderate thinking of his students who have extraordinary influence in Indonesia. The thought of fiqh and Sufism Shaykh Nawawi can foster tolerance, mutual respect amid differences, enthusiasm for work and discipline in all activities.
\end{abstract}

Keywords : Moderasi Beragama, Fiqh, Tasawuf, Nawawi Al-Banteni

\section{A. Pendahuluan}

Nama lengkap Syekh Muhammad Nawawi adalah Abu Abdul Mu'thi Alallamah Syekh Muhammad Nawawi bin Arabi bin Ali Al-Tanari AlBanteni Al-Jawi. Beliau dilahirkan di Banten Jawa Barat pada tahun 1813 Masehi dalam keluarga yang memiliki semangat tinggi dalam dakwah Islam. Orang tuanya memberi nama Muhammad Nawawi karena mengambil barokah dari dua insan mulia idola umat Islam yaitu Nabi Muhammad SAW dan Imam Nawawi al-Dimasyqi pengarang kitab 
Majmuk. ${ }^{1}$

Syekh Nawawi Banten merupakan ulama yang memiliki produktifitas yang tinggi dalam dunia tulis menulis. Karya tulisnya kurang lebih 115 kitab dalam berbagai bidang ilmu seperti tafsir, hadits, fiqh, ushul fiqh, tauhid, tasawwuf, nahwu, dan tasrif. Karya-karya beliau dibaca dan kaji dengan baik di berbagai pesantren di Indonesia. Nama beliau telah masyhur tidak hanya di Nusantara, bahkan di berbagai belahan dunia.

Karya tulis beliau yang berjudul Tafsir Munir Li Ma`alim at-Tanzil al-Mufassir 'an Wujuhi Mahasin at-Ta'wil mendapatkan apresiasi yang luar biasa dari para ulama di Mesir. Berkat karya inilah beliau sangat dihormati dan dimulyakan dan beliau mendapatkan kedudukan mulia dengan gelar Sayyid Ulama Hijaz. Gelar ini merupakan pencapaian luar biasa yang memang pantas disandang oleh Syekh Muhammad Nawawi yang menguasai berbagai disiplin ilmu.

Namun, kepandaian dan kedalaman ilmunya tidak membuatnya sombong dan bangga diri. Beliau merupakan ulama yang sangat zuhud dan tawadhu`. Hal ini bisa dilihat dari beberapa pendahuluan di kitabkitabnya. Misalnya dalam kitab Kasifat al-Saja beliau menyebut dirinya sebagai orang yang membutuhkan rahmat Allah karena banyak melakukan kesalahan dan kekeliruan serta mengatakan bahwa tujuannya menulis kitab ini adalah sebagai pengetuk hati bagi orang-orang yang lengah sepertiku. $^{2}$

Syekh Muhammad Nawawi sangat tangkas dan lincah dalam mengulas persoalan-persoalan keilmuan. Syekh Nawawi Merupakan seorang Ghazalian. Hal ini terlihat dari pemilihan beliau untuk memberikan penjelasan terhadap kitab al-Ghazali Bidayatul Hidayah. Karya tersebut diberi nama Maraqil Ubudiyah yang banyak mengulas masalah-masalah fiqh yang dipadukan dengan tasawwuf. Beliau merupakan ulama yang memang piawai menyatukan fiqh dan tasawwuf. Terbukti dalam karyanya al-Futuhat al-Madaniyah. Secara subtansi, karya ini merupakan gabungan dari kitab Ibnu Arabi al-Futuhat al-Makkiyah dan kitab al-Syu'abul Imaniyah karya ulama Asy`ariyah Syafi iyyah Imam Jalaluddin al-Suyuthi. ${ }^{3}$

Al-Ghazali merupakan tokoh yang telah diterima dengan baik oleh

1 Mastuki HS dan M Ishom El-Saha (editor), Intelektualisme Pesantren, (Jakarta: Diva Pustaka, 2003), Seri 2, 113.

2 Syekh Nawawi bin Umar Al- Jawi, Kasyifatu As-Saja, (Jakarta: Darul Kutub Islamiyah, 2008), 7.

${ }^{3}$ Abdul Kadir Readi, Arkeologi Tasawwuf, (Jakarta: Mizan, 2016), 373.

$382 \mid$ JURNAL LISAN AL-HAL 
masyarakat muslim Indonesia. Oleh karena itulah tepat sekali pilihan Syekh Nawawi dalam memilih kitab al-Ghazali sebagai objek kajiannya. Tidak begitu dengan Ibnu Arabi yang dalam benak sebagian muslim Indonesia beliau diposisikan sebagai sosok dengan pemikiran kontroversial, terlalu rumit dan filosofis.

Namun di tangan Syekh Nawawi kedua tokoh ini ditampilkan sebagai tokoh yang sama baiknya. Beliau mengutip pemikiran al-Ghazali dan mengutip pula pemikiran Ibnu Arabi. Bahkan dalam al-Futuhat Madaniyah beliau menyandingkan Ibnu Arabi dan Jalaluddin Al-Suyuti. Tentu ini merupakan pencapaian luar biasa yang tidak semua orang bisa melakukannya. Kedalaman pemahaman fiqh dan tasawwufnya yang moderat sangat berperan dalam kehidupannya untuk mendamaikan ilmuilmu dan para tokoh serta mewujudkan perdamaian di tengah-tengah masyarakat. Lantas Apa saja nilai-nilai moderasi dalam pemikiran fiqh dan tasawwuf Syekh nawawi Banten? Bagaimanakah pengaruh pemikiran fiqh dan tasawwuf Syekh Muhammad Nawawi Banten dalam membentuk karakter bangsa dan mewujudkan perdamaian?

\section{B. Pembahasan}

\section{Tasawwuf dan Fiqh}

Para ulama sufi berbeda pendapat tentang asal usul penggunaan kata tasawuf. Dari beberapa referensi buku-buku tasawuf, paling tidak ditemukan lima pendapat tentang asal kata tasawuf. ${ }^{4}$ Pertama, tasawuf berasal dari kata shuf, yang berarti bulu domba. Berasal dari kata shuf karena orang-orang ahli ibadah dan zahid pada masa dahulu menggunakan pakaian sederhana terbuat dari bulu domba. Dalam sejarah tasawuf banyak kita dapati cerita bahwa ketika seseorang ingin memasuki jalan kedekatan pada Allah mereka meninggalkan pakaian mewah yang biasa dipakainya dan diganti dengan kain wol kasar yang ditenun sederhana. Tradisi pakaian sederhana dan compang camping ini dengan tujuan agar para ahli ibadah tidak timbul rasa riya', ujub atau sombong .5

Kedua, kata tasawuf dihubungkan kepada perkataan ahl shuffah, yaitu sebutan yang disematkan kepada sebagian fakir miskin dari kalangan orang Islam pada masa awal Islam. diantara mereka adalah orang-orang yang tidak memiliki tempat tinggal, maka menempati sebuah

4 Muhammad Hafiun, Teori Asal Usul Tasawuf, (Jurnal Dakwah, Vol. XIII, No. 2 Tahun 2012), 242-243

5 Muhammad Sholikhin, Tradisi Sufi dari Nabi, (Cakrawala: Yogyakarta, 2009), 19.

$$
\text { JURNAL LISAN AL-HAL } \mid 383
$$


gubuk yang telah dibangun oleh Rasulullah di luar masjid di kota Madinah. ${ }^{6}$

Ahl al-Shuffah adalah sebuah kumpulan umat Islam yang memiliki ciri khas menyibukkan diri dengan kegiatan ubudiyah. Mereka memilih meninggalkan kehidupan dunia dan memilih pola hidup zuhud. Mereka menetap di masjid Nabi dan tidur di atas bangku batu dengan memakai pelana. Mereka memang miskin namun berhati mulia. Para sahabat nabi hasil produk shuffah ini antara lain Abu Darda', Abu Dzar al Ghifari dan Abu Hurairah. ${ }^{7}$

Ketiga, tasawuf berasal dari kata shofi, yang memiliki arti orang suci atau orang-orang yang mensucikan dirinya dari hal-hal yang bersifat duniawi .8 Mereka memiliki ciri-ciri khusus dalam kegiatan dan ibadah mereka atas dasar kesucian hati dan untuk pembersihan jiwa dalam rangka mendekatkan diri kepada Allah. Mereka adalah orang yang selalu menjaga dirinya dari perbuatan dosa dan maksiat. Pendapat yang keempat mengatakan bahwa tasawuf berasal dari kata shaf, yaitu orang-orang yang selalu berada di barisan depan dalam beribadah kepada Allah dan dalam melaksanakan kebajikan.

Sementara pendapat yang lain mengatakan bahwa tasawuf bukan berasal dari bahasa Arab namun berasal dari bahasa Yunani, yaitu sophia, yang artinya hikmah atau filsafat. Menisbahkan dengan kata sophia karena jalan yang ditempuh oleh para ahli ibadah memiliki kesamaan dengan cara yang ditempuh oleh para filosof. Mereka sama-sama mencari kebenaran yang berawal dari keraguan dan ketidakpuasan jiwa. Contoh ini pernah dirasakan dan dialami oleh sufi besar Iman al Ghazali dalam mengarungi dunia tasawuf.

Masih terdapat beberapa pendapat yang menghubungkan kata tasawuf dengan pendapat-pendapat lain yang dapat dirujuk dalam kitabkitab tasawuf. Meskipun demikian, yang jelas dari segi bahasa terlepas dari berbagai pendapat yang ada, dapat dipahami bahwa tasawuf adalah sikap mental yang selalu memelihara kesucian jiwa, beribadah, hidup qonaah, rela berkorban untuk kebaikan dan selalu bijaksana serta mengutamakan kebajikan.

Menurut istilah, selanjutnya tasawuf dari aspek terminologis juga didefinisikan secara beragam, dan dari berbagai sudut pandang. Hal ini

${ }^{6}$ Abul `Alaa `Afify, Tashawwuf al Islam wa Tarikhikhi, (Iskandariyah: Lajnah al Ta'lif wa al-Tarjamah wa al Nasyr, 1999), 6.

${ }^{7}$ Muhammad Sholikhin, Tradisi Sufi dari Nabi, (Yogyakarta: Cakrawala, 2009), 19.

8 Alwan Khoiri,et, al-Akhlak/Tasawuf, (Yogyakarta: Pokja Akademik UIN Sunan Kalijaga, 2005), 29

$384 \mid$ JURNAL LISAN AL-HAL 
dikarenakan bebeda cara memandang aktifitas para kaum sufi. Ma'ruf al Karkhi mendefinisikan tasawuf adalah mengambil hakikat dan meninggalkan yang ada di tangan mahkluk ${ }^{9}$. Berbeda dengan pendapat Syekh Abu Bakar Al Kattani yang menyatakan bahwa tasawuf adalah budi pekerti. Barangsiapa yang memberikan bekal budi pekerti atasmu, berarti ia memberikan bekal bagimu atas dirimu dalam tasawuf"10. Selanjutnya Muhammad Amin Kurdi mendefinisikan tasawuf adalah "suatu yang dengannya diketahui hal ihwal kebaikan dan keburukan jiwa, cara membersihkannya dari yang tercela dan mengisinya dengan sifat-sifat terpuji, cara melaksanakan suluk dan perjalanan menuju keridhaan Allah dan meninggalkan larangannya."11

Menurut Syekh Abu Mahfuz Ma'ruf al-Kharkhi tasawuf adalah berusaha meraih hakikat dan meninggalkan segala apa yang berada di tangan para makhluk. Sedangkan dalam pandangan Syekh Dzunun al-Misri Sufi adalah orang yang mendahulukan Allah dan mengalahkan selain-Nya, maka Allah akan mendahulukan dia mengalahkan selainnya. Berbeda dengan Imam Abu Al Husain al-Nauri yang mengatakan bahwa tasawuf adalah meninggalkan segala keinginan hawa nafsu.

Memang perlu diakui bahwa sejak kemunculannya tidak ada seorangpun di kalangan ulama, cendikiawan maupun sufi yang memiliki otoritas mutlak untuk mendefinisikan tasawwuf. Hal ini terlihat dari banyaknya definisi yang dikemukakan bahkan satu dengan lainnya bisa berbeda. Tasawwuf termasuk sulit didefinisikan. Itu antara lain terjadi karena sifatnya yang subyektif. Pengalaman spiritual yang dialami oleh seorang individu sufi turut mewarnai dan menentukan makna tasawwuf. Pengalaman ini sering tidak dapat dipahami oleh orang lain atau bahkan pelakunya sendiri. ${ }^{12}$

Dengan demikian pengalaman spiritual yang dialami oleh seorang sufi dapat diartikan secara psikologis, moral, etis, filosofis dan bahkan sosial politik. Pelaku dan penafsir juga leluasa memaknai pengalaman tersebut. Karenanya, tasawwuf sebagaimana dijelaskan dalam buku "Arkeologi Tasawwuf" dapat bersinggungan dengan ilmu-ilmu lain seperti psikologi, ilmu etika, dan belakangan sosiologi dan antropologi. ${ }^{13}$

\footnotetext{
${ }^{9}$ AS-Suhrawardi, Awarif al_Ma 'rif (Singapura: Kamisy Ihya' 'Ulum al-Din, 2001), 313.

10 Al-Ghazali, Ihya' 'Ulum ad-Din, (Semarang: Toha Putra, 2001), 376.

11 Amin al-Kurdi, Tanwir al-Qulub fi Mu'amalah 'Alam al-Ghuyub, (Surabaya: Penerbit al-Hidayah, 2000), 406.

12 Abdul Kadir Readi, Arkeologi Tasawwuf, (Jakarta: Mizan, 2016), 9.

13 Ibid, 9.
} 
Minimal ada empat hal yang melatarbelakangi ulama dalam memunculkan tasawwuf. Pertama, taraf pemahaman masyarakat muslim terhadap agama semakin meningkat sehingga menuntut adanya eksplorasi terhadap aspek-aspek lain dalam syariat yang masih terpendam. Kedua, ilmu-ilmu induk dalam Islam terutama fiqh sudah mulai matang. Para ulama memandang perlu adanya pendekatan spiritual untuk melengkapi kematangan ilmu ini. Ketiga, para ulama resah akan perilaku masyarakat muslim yang tidak lagi mencerminkan nilai-nilai moral yang diajarkan oleh Nabi. Keempat, secara epistemologis para ulama merasa sudah saatnya ada satu bidang ilmu yang mewadahi fenomena pengalaman batin yang berakar pada intuisi tetapi tidak tercerabut dari basis wahyu dan akal.

Tasawwuf berbeda dengan fiqh, menurut Imam Syafi i fiqh adalah mengetahui hukum-hukum syar`i yang bersifat amali (praktis) dan diperoleh melalui proses istinbath hukum berdasarkan dalil-dalil yang terperinci. Dari definisi ini dapat dikemukakan bahwa fiqh merupakan hukum-hukum operasional yang sangat praktis dan aplikatif sebagai preskripsi dan panduan manusia mukallaf dalam menjalankan aktivitas kesehariannya dalam kehidupan beragama dan bermasyarakat. ${ }^{14}$

Seiring dengan perkembangan, fiqh terbagi dalam beberapa kategori, mulai fiqh ibadah, muamalat, munakahat, qodho', fiqh tata negara, fiqh lingkungan, fiqh pertanahan dan lain sebagainnya. Fiqh sangat erat kaitannya dengan dalil dan wahyu, sedangkan tasawwuf lebih kepada pengalaman spiritual meskipun banyak juga dalil-dalil berkenaan dengan ritual-ritual keagamaan.

\section{Fiqh dan Tasawwuf Perspektif Syekh Muhammad Nawawi}

Syekh Muhammad Nawawi Banten sering kali memproklamirkan diri sebagai penganut paham Asy'ariyyah dan Maturidiyyah, sebuah paham teologi yang dilahirkan oleh Syekh Abu Hasan al-Asyari dan Abu Manshur al-Maturidi. Keduanya merupakan kelompok yang memfokuskan diri pada pembelajaran sifat-sifat Allah SWT. Dari Syekh Nawawi, paham tersebut pun kemudian menjadi tersebar di seantero Nusantara. Adapun dalam mazhab fiqh, syekh Nawawi memilih madzhab Imam Syafi'i untuk diikuti. Kehebatan beliau menghimpun karya dan pemikiran ulama-ulama besar di kalangan Mazhab Syafi'i membuatnya semakin terkenal. Hal ini terlihat dari karya-karyanya dalam ilmu fiqh.

Menurut Prof. Rosihon Anwar dalam tulisannya yang berjudul

${ }^{14}$ Abu Yasid, Epistemologi Fiqh, (Situbondo: Ibrahimy Pres, 2010), 130.

$386 \mid$ JURNAL LISAN AL-HAL 
“Reputasi Syekh Nawawi Tak Diragukan”, Syekh Nawawi juga mempelajari ilmu tasawuf dan mengajarkannya. Ia bahkan menulis sebuah karya yang menjadi rujukan utama seorang sufi, semisal Imam al-Ghazali. Dari sisi sufistik atau tasawuf, Syekh merupakan gelar tertinggi dalam tarekat. Pemikiran beliau merupakan pedoman dan rujukan bagi penggiat dan penganut tarekat di nusantara. Dari karyanya, Nawawi menunjukkan bahwa dia adalah seorang sufi brilian, ia banyak memiliki tulisan di bidang tasawuf yang dapat dijadikan sebagai rujukan standar bagi seorang sufi.

Karya Nawawi yang dapat merepresentasikan pandangan tasawufnya seperti Misbah al-Zulam, Qami' al-Thugyan, dan Salalim al Fudala. Selain itu, ia juga banyak sekali merujuk kitab Ihya 'Ulumuddin karya al-Ghazali, kitab yang merupakan rujukan penting bagi setiap tarekat. Dalam kitab Qami' al-Thugyan Syekh Nawawi selain memaparkan persoalan-persoalan tasawwuf, beliau juga menyajikan persoalanpersoalan akidah dan fiqh. Jika dilihat dari beberapa karyanya, sepertinya beliau ingin memadukan antara ilmu akidah, syariat dan hakikat serta antara ilmu fiqh dan tasawwuf.

Pernyataan ini bisa dibuktikan misalnya ketika membaca karyanya Bahjatul Wasail Bisyarhi Masail. Di sana disebutkan bahwa kitab yang mensyarahi karya Sayyid ahmad bin Zaini al-Habsy ini merupakan perpaduan antara ilmu ushuluddin, fiqh dan tasawwuf. Kitab ini diawali tentang pembahasan ilmu, kemudian rukun islam, rukun iman, kemudian masalah-masalah yang berkenaan dengan fiqh dan tasawwuf. ${ }^{15}$

Dalam kitab Kasifatu Saja beliau juga memadukan antara ushuluddin dan fiqh. Diawali dengan pembahasan keimanan, keislaman, dan ditutup dengan persoalan yang berkaitan denga fiqh. Kitab Maraqil Ubudiyah juga merupakan karya yang memadukan antara fiqh dan tasawwuf. Ini membuktikan bahwa Syekh Nawawi merupakan sosok ulama yang tidak membeda-bedakan ilmu. Semuanya mendapatkan kedudukan sama di mata beliau. Antara satu ilmu dan yang lain tidak perlu dipertentangkan, bahkan jika mungkin dipadukan, maka harus dipadukan.

Pada masa Syekh Nawawi memang ada banyak orang yang memiliki tipe memisah-misahkan ajaran Islam. Sebagian mereka ada yang condong kepada salah satu ilmu saja tanpa menganggap penting ilmu lainnya. Ada juga yang menguasai ilmu agama tanpa disertai pemahaman dan memandang hakikat sebagai entitas yang terpisah dari syariat atau

15 Syekh Muhammad Nawawi Banten, Bahjatul Wasail Bisyarhi Masail, (Jakarta: Darul kutub Islamiyah, 2008), 5. 
sebaliknya. ${ }^{16}$

Dalam Maraqil Ubudiyah beliau secara tegas beliau menolak pandangan bahwa hakikat cukup tanpa syariat. Padahal syariat adalah bagian luar sedangkan hakikat adalah bagian dalam. Syariat tanpa hakikat adalah sia-sia dan hakikat tanpa syariat adalah tidak diterima.

Apa yang disampaikan oleh Syekh Nawawi ini sesuai dengan perkataan ulama semisal Imam Malik yaitu,

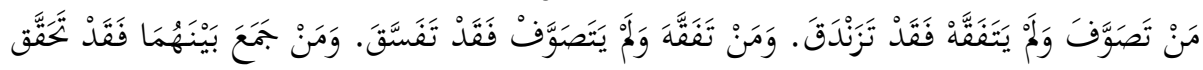

"Barang siapa yang bertasawwuf tanpa fiqh, maka dia zindik dan barang siapa yang mengamalkan fiqh tanpa tasawwuf, maka dia fasik dan barang siapa yang memadukan keduanya, maka dia sungguh tahqiq (benar).

Jika diumpamakan, fiqh bagaikan jasad dan tasawwuf sebagai ruhnya. Keduanya harus dipadukan dan disatukan serta diamalkan secara bersamaan. Jika tidak demikian, maka akan terjadi kesalahan fatal yang sulit untuk dimaafkan.

\section{Nilai-Nilai Moderasi dalam Pemikiran Fiqh dan Tasawwuf Syekh Muhammad Nawawi}

Moderasi Islam menjadi penting untuk dikembangkan, karena sikap moderat dianggap sebagai jalan tengah dalam memecahkan masalah. Seorang muslim moderat senantiasa memandang moderasi sebagai sikap yang paling adil dalam memahami agama. Hakikat ajaran Islam adalah kasih sayang, maka seorang muslim moderat senantiasa mendahulukan perdamaian dan menghindari kekerasan pemikiran atau tindakan. Seorang muslim moderat senantiasa memandang dan memperlakukan semua orang secara adil dan setara. Selain itu, kalangan muslim moderat senantiasa mengutamakan nilai-nilai kemanusiaan dan demokrasi, karena ajaran Islam mendorong agar demokrasi dijadikan alternatif dalam mewujudkan nilai-nilai kemanusiaan.

Moderasi Islam dalam bahasa arab disebut dengan al-Wasathiyyah al-Islamiyyah. Al-Qardawi menyebut beberapa kosakata yang serupa makna dengannya termasuk kata tawazun, i'tidal, ta'adul dan istiqamah. Sementara dalam bahasa inggris sebagai Islamic Moderation. Moderasi Islam adalah sebuah pandangan atau sikap yang selalu berusaha mengambil posisi tengah dari dua sikap yang berseberangan dan berlebihan sehingga salah satu dari kedua sikap yang dimaksud tidak mendominasi dalam pikiran dan sikap seseorang. Dengan kata lain

${ }^{16}$ Abdul Kadir Readi, Arkeologi Tasawwuf, (Jakarta: Mizan, 2016), 370.

388 JURNAL LISAN AL-HAL 
seorang Muslim moderat adalah Muslim yang memberi setiap nilai atau aspek yang berseberangan bagian tertentu tidak lebih dari porsi yang semestinya.

Adapun istilah moderasi menurut Khaled Abou el-Fadl dalam The Great Theft adalah paham yang mengambil jalan tengah, yaitu paham yang tidak ekstem kanan dan tidak pula ekstrem kiri. ${ }^{17}$ K.H. Abdurrahman Wahid pun merumuskan bahwa moderasi harus senantiasa mendorong upaya untuk mewujudkan keadilan sosial yang dalam agama dikenal dengan al-maslahah al-'ammah. Bagaimanapun hal ini harus dijadikan sebagai fondasi kebijakan publik, karena dengan cara yang demikian itu kita betul-betul menerjemahkan esensi agama dalam ruang publik. Dan setiap pemimpin mempunyai tanggung jawab moral yang tinggi untuk menerjemahkannya dalam kehidupan nyata yang benar-benar dirasakan oleh publik. ${ }^{18}$

Menurut Kiai Afifuddin Muhajir moderasi dalam Islam memiliki dua arti. Pertama, moderasi berarti bukan ini dan bukan itu. Misalnya konsep Islam tentang nafkah adalah jalan tengah antara kikir (taqtir) dan boros (israf), artinya Islam mengajarkan agar pemberi nafkah tidak kikir dan tidak boros, melainkan ada diantara keduanya. ${ }^{19} \mathrm{Hal}$ ini bisa dilihat dalam firman Allah surat Al-Isra',

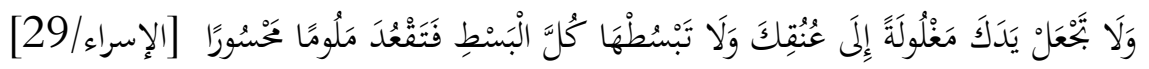

"Dan janganlah kamu jadikan tanganmu terbelenggu pada lehermu dan janganlah kamu terlalu mengulurkannya karena itu kamu menjadi tercela dan menyesal."

Arti kedua dari moderasi menurut Kiai Afifuddin Muhajir adalah bukan hanya ini dan bukan hanya itu, misalnya Islam antara jasmani dan rohani. Maksudnya Islam tidak hanya mengurusi masalah-masalah yang bersifat jasmani dan tidak hanya mengurusi yang rohani saja, tetapi mengurusi keduanya secara bersamaan. Contoh lain, Islam antara nash dan ijtihad. Artinya hukum Islam tidak hanya didasarkan pada nash semata, namun juga melibatkan aktifitas ijtihad. ${ }^{20}$ Untuk contoh yang terakhir ini dapat dilihat dari dialog antara Rasulullah dengan Muadz bin Jabal ketika diutus ke Yaman,

17 Zuhairi Misrawi, Hadratussyaikh Hasyim Asy'ari Moderasi, Keutamaan, dan Kebangsaan, (Jakarta: PT Kompas Media Nusantara, 2010), 13.

18 Ibid, 14.

19 Afifuddin Muhajir, Membangun Nalar Islam Moderat : Kajian Metodologis, (Situbondo: Tanwirul Afkar, 2018), 5.

20 Ibid, 6. 


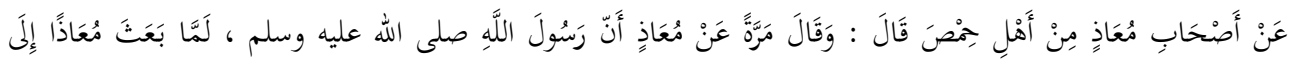

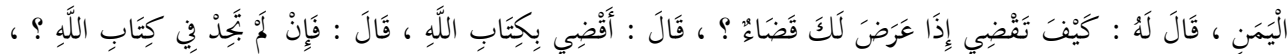

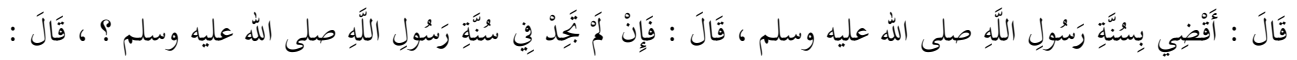

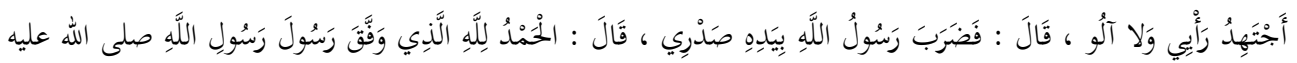

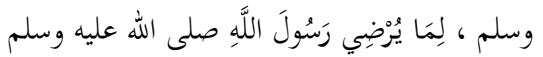

"Dari beberapa orang penduduk Himsh, diceritakan dari beberapa sahabat Mu'adz bin Jabal, bahwa sesungguhnya saat Rasulullah bermaksud mengutus Mu'adz untuk berdakwah ke negeri Yaman, beliau bertanya kepada Mu'adz: Bagaimana caramu memutuskan persoalan yang akan kamu hadapi? Mu'adz menjawab: saya akan memutuskannya berdasarkan Alquran. Nabi bertanya lagi: Jika dalam Alquran tidak Kamu temukan jawabannya? Mu 'adz menjawab: dengan Sunnah Rasulullah. Sang Nabi pun bertanya lagi: andaikata di dua sumber itu tidak dijumpai jawabannya? Mu'adz pun menjawab: Saya akan berijtihad dengan menggunakan akalku untuk menyelesaikan hal itu dan saya tidak akan ceroboh dalam berijtihad. Setelah itu, Rasulullah saw. menepuh dada Mu'adz (sebagai pertanda setuju dan bangga atas kecerdasan Mu'adz bin Jabal, seraya bersabda: Segala puji bagi Allah Yang telah memberi taufiq kepada utusannya Rasulullah (Mu`adz) sesuai yang dikehendaki oleh Rasulullah."21

Moderasi (wasathiyyah) merupakan ciri khas agama Islam yang merupakan perpaduan dan penyatuan dari konsep ta`adul, tawazun dan tawassuth. Ungkapan wasathiyyah bisa ditemukan dalam ayat Alquran dan Hadits Nabi berikut ini,

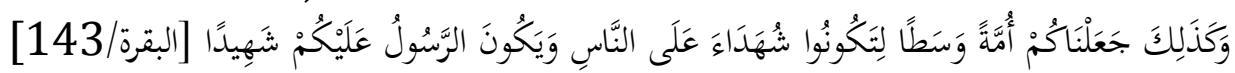

"Dan demikian (pula) Kami telah menjadikan kamu (umat Islam), umat yang adil dan pilihan agar kamu menjadi saksi atas (perbuatan) manusia dan agar Rasul (Muhammad) menjadi saksi atas (perbuatan) kamu." (AlBaqarah:143)

Sementara diantara hadits yang menjelaskan wasathiyyah yaitu,

$$
\text { خَيْرُ الُْْمُوْرِ اَوَْسَاطُهَا }
$$

"Sebaik-baik urusan adalah jalan tengahnya." Ada juga Hadits lain yang mirip dengan hadits di atas yaitu,

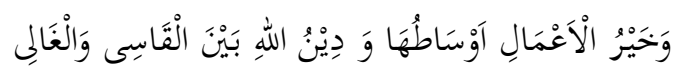

"Dan sebaik-baik amal perbuatan adalah yang tengah-tengah, dan agama

${ }^{21}$ Abu Dawud Sulaiman bin al-Asy"ats al-Sajistani, Sunan Abi Dawud, (Beirut: alMaktabah al-`Ashriyah, 2001), Juz III, 303.

$390 \mid$ JURNAL LISAN AL-HAL 
Allah ada diantara yang beku dan yang mendidih".

Dengan demikian, dapat disimpulkan bahwa moderasi merupakan ciri khas Islam yang memiliki ciri-ciri tawassuth, ta`adul dan tawazun dalam setiap pola fikir, pola bertindak, dan berperilaku. Pada tataran praktisnya, wujud moderat dalam Islam dapat diklasifikasi menjadi empat wilayah pembahasan, ${ }^{22}$ yaitu: 1). Moderat dalam persoalan aqidah; 2). Moderat dalam persoalan ibadah; 3). Moderat dalam persoalan perangai dan budi pekerti; 4) Moderat dalam persoalan pembentukan syariat.

Pada tataran yang lebih rinci bentuk-bentuk keseimbangan dalam Islam dapat diklasifikasikan ke dalam berbagai ragam pranata kehidupan beragama. Diantaranya adalah moderasi dalam ibadah, moderasi dalam aqidah, moderasi dalam fiqh, dan moderasi dalam tasawwuf. Penulis dalam kajian ini akan fokus kepada wasathiyah dalam pemikiran fiqh dan tasawwuf Syekh Nawawi Banten.

Diantara pemikiran fiqh moderat Syekh Nawawi Banten adalah toleran di tengah perbedaan pendapat madzhab. Dalam kitab-kitab Syafi iyah sering dijumpai ungkapan al khuruju minal khilaf mustahab (keluar dari perbedaan pendapat adalah lebih disukai). Kaidah ini sering diimplementasikan oleh Syekh Nawawi Banten sebagai upaya mengkompromikan pendapat-pendapat yang berbeda diantara beberapa madzhab.

Dalam kitab Kasifatu As-Saja misalnya, ketika Syekh Nawawi Banten membahas tentang sunah-sunah wudhu', beliau memasukkan addalku (menggosok-gosok anggota wudhu' dan membasuh seluruh rambut kepala sebagai bagian dari sunnah wudhu' ${ }^{\prime 23}$ Hal tersebut dilakukan untuk menengahi berbagai perbedaan pendapat diantara ulama dan sebagai implementasi dari kaidah al khuruju minal khilaf mustahab.

Syekh Nawawi dalam pemikiran fiqhnya juga akomodatif terhadap beberapa pendapat ulama. Beliau kadang-kadang mengungkapkan dengan begitu lengkap ragam pendapat ulama mengenai suatu persoalan. Dalam jumlah rukun sholat misalnya, beliau mengungkapkan bahwa terdapat beragam pendapat ulama mengenai jumlah rukun sholat, mulai dari 14, $15,17,18,19,20$ rukun. ${ }^{24}$ Beliau menjelaskan dengan baik mengenai sebab perbedaan dan sumber pendapat yang dikutip. Ini merupakan teladan yang baik dalam kejujuran intelektual dan apresiasi terhadap

${ }^{22}$ Abu Yazid, Membangun Islam Tengah : Refleksi Dua Dekade Mahad Aly Situbondo, (Yogyakarta: Lkis, 2010), 38.

${ }^{23}$ Syekh Nawawi bin Umar Al- Jawi, Kasyifatu As-Saja, (Jakarta: Darul Kutub Islamiyah, 2008), 36.

${ }^{24}$ Syekh Nawawi bin Umar Al- Jawi, Kasyifatu As-Saja, 89. 
pendapat-pendapat ulama.

Pemikiran moderat Syekh Nawawi Banten juga terlihat dari pendapatnya mengenai relasi muslim dan non muslim. Sebelum meninggal, Syekh Nawawi mempunyai pemikiran bahwa ketika orang kafir menjadi penjajah atau berbuat dhalim, maka umat Islam tidak boleh berhubungan dengan mereka. Sedangan orang kafir yang tidak menjajah, umat Islam diperbolehkan menjalin hubungan baik dan kerjasama untuk mencapai tujuan kebaikan dunia. Karena dalam pandangan Syekh Nawawi, manusia seluruhnya bersaudara, meskipun mereka kafir. ${ }^{25}$

Selanjutnya dalam bidang tasawuf, sebenarnya banyak sekali pemikiran Syekh Muhammad Nawawi Banten. Namun, hanya beberapa saja yang akan dipaparkan dalam tulisan ini. Salah satu konsep tasawwuf Syekh Muhammad Nawawi yang menurut penulis memuat nilai wasathiyah adalah berkenaan jaminan rezeki manusia antara tawakkal dan bekerja. Perlu diakui bahwa pemahaman yang salah tentang tawakkal dapat membuat umat Islam malas untuk bekerja dan berusaha.

Dalam al-Quran Allah berfirman yang artinya : "Tiada satupun dabbah (binatang melata) di bumi kecuali Allah tanggung rezekinya". Kemudian timbul pertanyaan, mengapa masih banyak orang miskin yang kelaparan dan bayi-bayi mungil kekurangan gizi, bukankah Allah akan memberikan jalan keluar dan memberikan rezeki yang tidak disangkasangka bagi orang yang bertakwa kepadaNya.

Mari kita mulai dengan membahas tentang kata-kata "miskin". Bentuk asal dari kata miskin adalah sakana yang artinya adalah diam atau tidak bergerak. Diperoleh kesan bahwa faktor utama penyebab kemiskinan adalah sikap berdiam diri, tidak mau bekerja dan berusaha. Hal ini akan lebih nampak ketika kita memahami makna dabbah sebagaimana yang tercantum dalam firman Allah di atas, yang arti harfiyahnya adalah yang bergerak/melata. Berarti yang dijamin rezekinya adalah siapa yang aktif bergerak mencari rezeki, bukan yang diam menanti tanpa adanya usaha yang berarti. ${ }^{26}$

Bekerja dan kegiatan ekonomi adalah ibadah dan jihad. Oleh sebab itu islam menganjurkan umatnya untuk memproduksi dan berperan dalam berbagai bentuk aktivitas ekonomi : Pertanian, perkebunan, perikanan, perindustrian, dan perdagangan. Islam memberkati pekerjaan dunia ini dan menjadikannya bagian dari ibadah dan jihad.

25 Mastuki HS dan M Ishom El-Saha (editor), Intelektualisme Pesantren, (Jakarta, Diva Pustaka, 2003), Seri 2, 120.

${ }^{26}$ Quraish Shihab, Membumikan Al-Quran, (Jakarta: Lentera Hati, 2009), 449-450.

$392 \mid$ JURNAL LISAN AL-HAL 
Suatu ketika Sayyidina Umar melewati sekelompok orang-orang, beliau bertanya, "Apa yang kamu laksanakan?" Mereka menjawab, "Kami bertawakkal." Umar berkata, "Bukan, tetapi kamu menggatungkan nasibmu kepada orang lain. Yang bertawakkal dengan sebenarnya ialah orang yang menaburkan benih di tanah lalu menyerahkan keberuntungannya kepada Allah."

Syekh Nawawi dalam Qomi` al-Thugyannya memberikan penjelasan yang luar biasa berkenaan dengan hal ini. Beliau mengutip pendapat ulama bahwa wajib hukumnya mencari rezeki yang halal baik melalui usaha pertanian, perdagangan dan industri. Orang tidak bekerja bisa disebabkan oleh tiga alasan yaitu malas, alasan takwa dan malu atau takut tantangan. ${ }^{27}$

Orang yang malas bekerja akan menjadi peminta-minta. Sedangkan orang yang tidak bekerja dengan alasan takwa akan menjadi orang yang berharap atas pemberian manusia dan makan dengan agamanya. Kemudian orang yang tidak bekerja karena alasan malu dan takut tantangan, maka akan menjadi pencuri yang mengganggu ketenangan masyarakat.

Diakhir ungkapannya dalam masalah bekerja ini, beliau menyampaikan bahwa bekerja sama dengan keharusan mencari ilmu. Hukum bekerja dalam pandangan Syekh Nawawi dibagi menjadi empat. Pertama, wajib bekerja untuk memenuhi kebutuhan minimal dirinya, keluarga dan agamanya. Kedua, sunnah bekerja untuk biaya tambahan untuk berderma dengan sesama. Ketiga, mubah bekerja untuk biaya tambahan dalam rangka mencari kenikmatan dan keindahan. Keempat, haram bekerja jika bertujuan untuk berbangga-bangga semata. ${ }^{28}$

Pemikiran Syekh Nawawi ini memiliki kontribusi yang sangat besar dalam membangkitkan etos kerja bangsa ini. Atas dasar inilah, bangsa Indonesia harus mulai bangkit dan membangun semangat baru demi kemajuan bangsa ini. Dengan pemikiran Syekh Nawawi ini, diharapkan bangsa ini dapat memiliki karakter yang moderat, ulet, tekun dan kreatif.

Pemikiran tasawwuf Syekh Nawawi lainnya misalnya berkenaan dengan kedisiplinan. Dalam Maraqil Ubudiyah ada pembahasan mengenai Adab al-Isti'dad Li Sairissholah yaitu tatakrama berkenaan dengan persiapan sholat. Dalam pembahasan ini beliau menganjurkan agar seorang muslim bersiap-siap untuk melaksanakan sholat lima waktu

27 Syekh Muhammad Nawawi Banten, Qomi`al-Thugyan, (Jakarta: Darul kutub Islamiyah, 2002), 12.

28 Ibid, 12. 
sebelum waktunya tiba. Hendaknya tiap hendak tiba waktu sholat jangan disibukkan dengan selain amal soleh. Di akhir pembahasan masalah ini, beliau berpesan agar tidak gembira kecuali karena bertambahnya ilmu dan amal soleh.

Menurut hemat saya, pemikiran ini adalah perpaduan antara fiqh dan tasawwuf. Perpaduan semacam ini banyak ditemukan dalam kitabkitab karya beliau. Dalam Kasifah al-Saja masalah zakat misalnya, beliau memiliki gagasan untuk segera dibayarkan apabila telah memenuhi syarat. Jika diakhirkan kemudian rusak, maka harus diganti sesuai kuantitas dan kualitas barang tersebut kemudian segera dibayarkan. ${ }^{29}$ Pemikiran ini tentunya sangat sosialis, karena dapat membantu orang-orang yang membutuhkan. Relasi antara orang kaya dan orang miskin harus dicairkan melalui kegiatan sosial semacam zakat. Zakat dapat menjadi ibadah yang memberikan solusi ekonomi bagi fakir miskin.

\section{Pengaruh Pemikiran Fiqh dan Tasawwuf Syekh Muhammad Nawawi Banten dalam Menciptakan Moderasi Beragama dan Perdamaian}

Di kalangan komunitas pesantren Syekh Nawawi tidak hanya dikenal sebagai ulama penulis kitab, tapi juga ia adalah mahaguru sejati (the great scholar). Syekh Nawawi telah banyak berjasa meletakkan landasan teologis dan batasan-batasan etis tradisi keilmuan di lembaga pendidikan pesantren. Ia turut banyak membentuk keintelektualan tokohtokoh para pendiri pesantren yang sekaligus juga banyak menjadi tokoh pendiri organisasi Nahdlatul Ulama (NU).

Apabila KH. Hasyim Asyari sering disebut sebagai tokoh yang tidak bisa dilepaskan dari sejarah berdirinya NU, maka Syekh Nawawi adalah guru utamanya. Di sela-sela pengajian kitab-kitab karya gurunya ini, seringkali KH. Hasyim Asyari bernostalgia bercerita tentang kehidupan Syekh Nawawi, kadang mengenangnya sampai meneteskan air mata karena besarnya kecintaan beliau terhadap Syekh Nawawi.

Setelah beliau menghasilkan berbagai macam karya, tentunya juga banyak memberikan pengaruh terhadap perkembangan hukum Islam dan pembentukan karakter bangsa. Kesantunan dan ketawadhuan Syekh Nawawi telah membawa manfaat besar dalam pembentukan karakter bangsa ini.

Secara umum, menurut para peneliti, beberapa keistimewaan karya

29 Syekh Nawawi bin Umar Al- Jawi, Kasyifatu As-Saja, (Jakarta: Darul Kutub Islamiyah, 2008,) 186.

$394 \mid$ JURNAL LISAN AL-HAL 
Syekh Nawawi adalah bagaimana ia mampu untuk menghidupkan isi karangan sehingga dapat dijiwai oleh pembaca, kemudian pemakaian bahasa yang relatif mudah dipahami, sehingga mampu menjelaskan istilah-istilah yang sulit, dan yang tidak kalah pentingnya adalah keluasan isi karangannya.

Pemikiran-pemikiran Syekh Nawawi, khususnya dalam masalah fiqh dan tasawwuf banyak memberikan pengaruh dalam menciptakan pemikiran wasathiyah, mewujudkan perdamaian dan pembentukan karakter bangsa. Hal ini dapat terlihat dari pemikiran-pemikiran moderat murid-muridnya yang tersebar di Indonesia. KH. Kholil Bangkalan misalnya, sepulangnya dari Tanah Arab, beliau dikenal sebagai sebagai seorang ahli fiqh dan tarekat. Bahkan pada akhirnya, beliau dikenal sebagai salah seorang Kiai yang dapat memadukan kedua hal itu dengan serasi.

KH. Hasyim Asy`ari juga sebagai murid Syekh Nawawi Banten banyak memberikan pengaruh dalam pembentukan karakter bangsa. Kiai Hasyim mengarang sebuah kitab tentang pendidikan dengan judul Adab Alim Wal Muta`allim. Kiai Hasyim menulis kitab ini di dasari oleh kesadaran akan perlunya literatur yang membahas tentang etika dalm mencari ilmu pengetahuan.

Dalam konsep pendidikan ala Kiai Hasyim, karakter pemikirannya adalah mengetengahkan nilai-nilai estetis yang bernafaskan sufistik. Kecendrungan ini dapat terbaca dalam gagasan-gagasannya, misalnya dalam keutamaan menuntut ilmu. Untuk mendukung itu dapat dikemukakan bahwa bagi $\mathrm{KH}$, Hasyim Asy`ari keutamaan ilmu yang sangat istimewa adalah bagi orang-orang yang benar-benar Lillahi ta'ala. Kemudian, ilmu dapat diraih jika jiwa orang yang mencari ilmu tersebut suci dan bersih dari segala sifat jahat aspek-aspek keduniaan. ${ }^{30}$

Pemikiran fiqh dan tasawwuf Syekh Nawawi Banten dapat memberikan pengaruh besar melalui tokoh-tokoh yang pernah menimba ilmu kepada beliau. KH. Kholil Bangkalan dan KH. Hasyim Asy`ari merupakan dua tokoh besar yang alim, wara` dan sufi. Kedua tokoh ini telah banyak memberikan pengaruh terhadap keutuhan bangsa dan negara ini.

Pemikiran Syekh Nawawi Banten untuk memadukan antara fiqh dan tasawwuf ini memberikan kontribusi besar, diantaranya tidak adanya dikotomi satu bidang ilmu dengan ilmu lainnya, tumbuhnya sikap saling

30 Mastuki HS dan M Ishom El-Saha (editor), Intelektualisme Pesantren, (Jakarta, Diva Pustaka, 2003), Seri 2, 323. 
menghormati meskipun ada perbedaan pendapat, kesadaran untuk memadukan antara ibadah ritual dan ibadah sosial, semangat untuk berusaha dan tawakkal dan lain sebagainya.

\section{Simpulan}

Setelah melakukan analisis terhadap data-data berkaitan nilai-nilai moderasi dalam pemikiran fiqh dan tasawwuf Syekh Nawawi Banten serta pengaruhnya dalam membentuk karakter bangsa dan menciptakan perdamaian diperoleh kesimpulan sebagai berikut: Pertama, Dalam pandangan Syekh Nawawi Banten, fiqh dan tasawwuf tidak boleh dipisahpisah. Keduanya bagaikan ruh dan jasad yang saling menyatu satu dengan lainnya. Dalam karya-karyanya yang banyak memadukan antara fiqh dan tasawwuf beliau mengajarkan agar ada keseimbangan antara tawakkal dan bekerja, ibadah sosial dan ibadah ritual, meletakkan semua ilmu secara sejajar, memposisikan tokoh-tokoh Islam dengan baik. Nilai-nilai moderasi dalam pemikiran fiqhnya diantaranya adalah selalu berusaha meminimalisir perbedaan pendapat, toleran di tengah perbedaan pendapat madzhab, berhati-hati(ihtiyath) dalam menetapkan hukum, serta tidak fanatik madzhab. Sedangkan diantara pemikiran moderatnya dalam tasawwuf adalah ajaran tentang perpaduan antara syariat, thariqot dan hakikat, antara tawakkal dan ikhtiyar dalam mencari rezeki,

Kedua, Nilai-nilai moderasi dalam pemikiran fiqh dan tasawwuf Syekh Nawawi Banten sangat berpengaruh dalam membentuk karakter bangsa dan menciptakan perdamaian. Hal ini dapat terlihat dari pemikiran moderat murid-muridnya yang memiliki pengaruh luar biasa di Indonesia. Pemikiran fiqh dan tasawwuf Syekh Nawawi dapat menumbuhkan toleransi, saling menghormati di tengah perbedaan, semangat bekerja dan kedisiplinan dalam segala aktivitas.

\section{DAFTAR PUSTAKA}

`Afify, Abul `Alaa, Tashawwuf al Islam wa Tarikhikhi, Iskandariyah: Lajnah al Ta'lif wa al-Tarjamah wa al Nasyr, 1999.

Al-Ghazali, Ihya' 'Ulum ad-Din, Semarang: Toha Putra, 2001.

Al-Kurdi, Amin, Tanwir al-Qulub fi Mu'amalah 'Alam al-Ghuyub, Surabaya: Penerbit al-Hidayah, 2000.

As-Suhrawardi, Awarif al_Ma'rif. Singapura: Kamisy Ihya' 'Ulum al-Din, 2001.

Hafiun, Muhammad, Teori Asal Usul Tasawuf, Jurnal Dakwah, Vol. XIII, No. 2 Tahun 2012.

$396 \mid$ JURNAL LISAN AL-HAL 
HS, Mastuki dan El-Saha, M Ishom (editor), Intelektualisme Pesantren, Jakarta: Diva Pustaka, 2003.

Khoiri, Alwan,et, al-Akhlak/Tasawuf, Yogyakarta: Pokja Akademik UIN Sunan Kalijaga, 2005.

Misrawi, Zuhairi, Hadratussyaikh Hasyim Asy'ari Moderasi, Keutamaan, dan Kebangsaan, Jakarta: PT Kompas Media Nusantara, 2010.

Nawawi, Syekh Muhammad bin Umar Al- Jawi, Bahjatul Wasail Bisyarhi Masail, Jakarta: Darul kutub Islamiyah, 2008.

Nawawi, Syekh Muhammad bin Umar Al- Jawi, Kasyifatu As-Saja, Jakarta: Darul Kutub Islamiyah, 2008.

Nawawi, Syekh Muhammad bin Umar Al- Jawi, Qomi` al-Thugyan, Jakarta: Darul kutub Islamiyah, 2002.

Muhajir, Afifuddin, Membangun Nalar Islam Moderat : Kajian Metodologis, Situbondo: Tanwirul Afkar, 2018.

Readi, Abdul Kadir, Arkeologi Tasawwuf, Jakarta: Mizan, 2016.

Shihab, Quraish, Membumikan Al-Quran, Jakarta: Lentera Hati, 2009.

Sholikhin, Muhammad, Tradisi Sufi dari Nabi, Yogyakarta: Cakrawala, 2009.

Yasid, Abu, Epistemologi Fiqh, Situbondo: Ibrahimy Pres, 2010.

Yasid, Abu, Membangun Islam Tengah: Refleksi Dua Dekade Mahad Aly Situbondo, Yogyakarta: Lkis, 2010. 
"Konsep Moderasi Beragama Syekh Nawawi Al-Banteni "

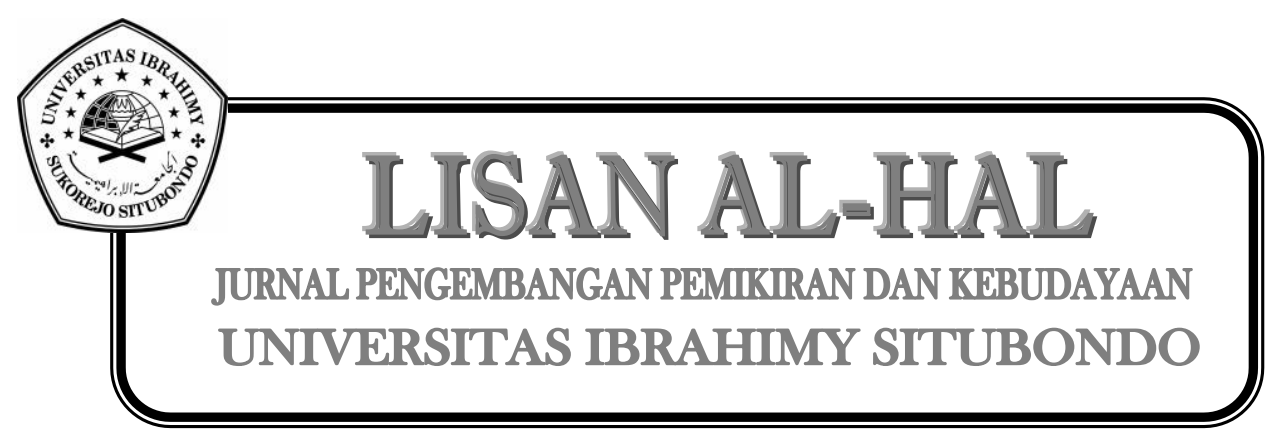

398 JURNAL LISAN AL-HAL 